\title{
Akut Generalize Ekzantematöz Püstülozis
}

\author{
Acute Generalized Exanthematous Pustulosis
}

\begin{abstract}
OZZET
Hikmet Tekin Nacaroğlu, Demet Can

Dr. Behçet Uz Çocuk Hastalıkları ve Cerrahisi Eğitim Ve Araştırma Hastanesi, Çocuk Alerji Ve Immunoloji Kliniği, Izmir, Türkiye

\footnotetext{
Yazışma Adresi/Address for Correspondence Dr. Hikmet Tekin Nacaroğ/u Dr. Behçet Uz Çocuk Hastallkları ve Cerrahisi Eğitim Ve Araştırma Hastanesi, Çocuk Alerii Ve Immunoloji Kliniği, Izmir, Türkiye Tel.: +902324116319 E-posta: tekin212@gmail.com

Geliş Tarihi/Received: 12.12 .2012 Kabul Tarihi/Accepted: 14.02.2013 tarafindan basılmış̧tr. Galenos Publishing.
}

(c) Güncel Pediatri Dergisi, Galenos Yayınevi

(c) The Journal of Current Pediatrics, published by

Akut generalize ekzantematöz püstülozis (AGEP), klinik olarak ani bașlayan, ateşle birlikte tüm vücutta yaygın püstüler döküntü ile seyreden nadir bir dermatozdur. Vakaların \%90'nında ilaç kullanım öyküsü mevcut olmakla birlikte etyopatogenezde nadiren viral ve bakteriyel enfeksiyonlar ile civaya karşı aşııı duyarlılık reaksiyonları da suçlanmaktadır. Klinik olarak eritemli zemin üzerinde, foliküler yerleşimli olmayan, çok sayıda steril püstülle karekterizedir. Hastalığın spesifik bir tedavisi yoktur, altta yatan nedenin ortadan kaldırıması ile spontan iyileşme gözlenir. Bu makalede AGEP'in etiyolojik, klinik ve histopatolojik özellikleri gözden geçirilmiştir. (Güncel Pediatri 2013; 11: 77-80)

Anahtar kelimeler: Akut generalize ekzantematöz püstüloz, ilaç hipersensitivitesi, çocukluk çağı

\section{SUMMARY}

Acute generalized exanthematous pustulosis (AGEP) is a rare cutaneous rash characterized by the abrupt onset of a widespread generalized pustular rash often accompanied by fever. In the etiopathogenesis, there is a history of drug use in $90 \%$ of the cases, and occasionally hypersensitivity reactions to mercury or viral and bacterial infections are accused. Nonfollicular eruptions on a erythematous surface spreading on a large scale are clinical features. There is no specific treatment when underlying cause cured spontaneous healing occures. AGEP's etiology clinical and histopathologic characteristics are reviewed here. (Journal of Current Pediatrics 2013; 11: 77-80)

Key words: cute generalized exanthematous pustulosis, drug hypersensitivity, childhood

\section{Giriş}

Akut generalize ekzantematöz püstülozis (AGEP), ilk kez 1980 yılında Beylot ve arkadaşları (1) tarafından "generalize püstüler psöriazise çok benzemekle birlikte sıklıkla ilaçlara bağlı olarak gelişen farklı bir püstüler ilaç erupsiyonu" olarak tanımlanmıştır $(1,2)$. Sistemik ateşle birlikte eritemli ve ödemli zemin üzerinde çok sayıda püstüler lezyonlarla seyreden AGEP'in görülme sıklığı yilda 1-5:1.000.000'dur (3). European Study of Severe Cutaneous Adverse Reactions (EuroSCAR) çalışmasının ortaya koyduğu tanı skorlaması ile püstüler psoriasis başta olmak üzere diğer püstüler erupsiyonlardan ayırıcı tanısı yapılmıştır. Etiyolojisinde ilk sırada ilaçlar sıklıkla da antibiyotikler bildirilmekle birlikte viral ve bakteriyel enfeksiyonlar ile civaya karşı aşırı duyarlılık reaksiyonları da suçlanmaktadır (2-5).

Etyoloji

Vakaların \%90'nında ilaç kullanım öyküsü mevcuttur $(1,2)$. Antibiyotikler AGEP'e en sık neden olan ajanlardır (\%65). Özellikle beta laktam grubu antibiyotikler (\%22) ve makrolidler (\%24) başta olmakla birlikte tetrasiklinler, kinolonlar, aminoglikozidler ve sülfonamidler AGEP'e en sık neden olan ajanlar olarak bildirilmiştir. AGEP'e neden olan diğer ilaçlar arasında, metronidazol, nistatin, izoniazid, furosemid, diltiazem, nonsteroid antiinflamatuvar ilaçlar, kodein, deksametazon, karbamazepin ve fenitoin gibi antikonvülzan ilaçlar belirtilmiştir (1-5). Sistemik ilaçların dıșında özellikle Parvovirüs B19, Coxsackie virüs B4, Epstein Barr virüsü, Sitomegalovirüs, Hepatit $B$ virüsü gibi viral enfeksiyonlar ile Mycoplasma pneumonia, Chlamydia pneumonia ve Escherichia coli gibi bakteriyal enfeksiyonlar, civa maruziyeti ve PUVA tedavisi AGEP etyolojisinde yer almaktadır (2-0).
\end{abstract}




\section{Patogenez}

AGEP'in patogenezi tam olarak anlaşılmamakla birlikte yardımcı T hücreleri tarafından salınan sitokinlerin ve ilaca ya da enfeksiyona bağlı antijen-antikor komplekslerinin deride birikimi suçlanmaktadır. Vakaların çoğunda şüpheli ilacın topikal formuyla uygulanan yama testlerinin pozitif reaksiyon vermesi tip IV aşırı duyarlıık reaksiyonunun da hastalığın patogenezinde rol aldığını düşündürmektedir (13). Son zamanlarda yapılan çalışmalarda deride ve dolaşımda ilaç ile ilişkili $T$ hücre klonlarının ürettiği, güçlü bir nötrofil kemoatraktan sitokin olan interlökin-8 (IL-8) üretiminin AGEP gelişiminde önemli rol oynadığı kanıtlanmıştır (14). Halevy ve arkadaşlarının (14) yaptığı 102 serilik bir çalışmada etyopatogenezde rol oynayan dört anahtar özellik üzerinde durulmuştur;

1- AGEP'li hastaların üçte birinde deride, püstül içinde ve dermiste eozinofil infiltrasyonu ile kanda eozinofili birlikte görülmektedir. Dokuda ve kanda eozinofil varlığı AGEP'in bir hipersensitivite reaksiyonu, büyük olasılıkla da ilaç ile ilişskili bir reaksiyon olduğunu gösteren bir bulgu olarak kabul edilmiştir. AGEP'deki bu eozinofili, IL-8/CXCL8 üreten $\mathrm{T}$ hücre klonlarının Th-2 cevabını artırmasıyla açıklanmıştır.

2- AGEP'de görülen nekrotik keratinosit varlığı diğer ilaç ile ilişkili erupsiyonlarda da bildirilmiştir. Bu nekrotik keratinositlerin sitotoksik ilaca spesifik $\mathrm{T}$ hücreler tarafından yapıldığı gösterilmiştir.

3- AGEP'de görülen nötrofilik inflamasyon ilaç reaksiyonlarında pek görülmez. Dermal nötrofil varlığı ilaca spesifik $T$ hücre (CD4+ ve CD8+) tarafından salınan güçlü bir nötrofil kemoatraktan sitokin olan IL-8/CXL8 varlığı ile açıklanmıştır. T hücrelerinden salınan IL8/CXCL8 tarafından üretilen faktörlerin, nötrofil apoptozisini azaltarak nötrofil yaşamını kolaylaştırmak yoluyla AGEP'teki steril püstüler erüpsiyonlara neden olduğu bildirilmiş̧tir.

4- Illacın tetiklediği AGEP erüpsiyonlarında görülen orta-derin dermal perivasküler infiltrasyon ve eritrosit ekstravazasyonu da etyolojide ilaç hipersensivitesinin rol oynayabileceğini göstermektedir.

\section{Klinik Bulgular}

Klinik olarak AGEP akut başlayan ateş ile beraber ödemli, kaşıntılı ve eritemli yüzeyde beliren, geniş yayılım yapan, yer yer birleşmeler gösteren, foliküler olmayan, 5 mm'den küçük çok sayıda steril püstüler lezyon ile karakterizedir. Klinik bulgular şüpheli ilaç kullanımı sonrası genellikle ilk 24 saat içinde başlar, ancak bazı olgularda klinik bulguların çıkması 3 haftaya kadar uzayabilir $(11,12,14)$. Lezyonlar özellikle yüz ile beraber parmak aralarından başlar ve saatler içerisinde gövde ve ekstremitelere yayllır $(4,14)$. Bazen püstüller birleşir ve yalancı Nikolsky bulgusuna sebep olabilir $(8,14)$. Hastalar yüzde oluşan ödem, purpura, atipik olan hedef lezyonlar ve büller gibi diğer deri bulguları ile de gelebilir. Ancak genelde bu döküntüler AGEP için tipik değildir. Olguların \%25'inde muköz membranların tutulumu görülebilir ve genelde avuç içi ve ayak tabanları tutulmaz $(9,11-4)$. Hastalarda genellikle $38^{\circ} \mathrm{C}$ ve üzerinde ateş görülür ve vakaların \%80'ninde $7000 / \mathrm{mm}^{3}$ üzerinde olan nötrofili bulunur. Vakaların üçte birinde hafif eozinofili bildirilmiștir (2,4,12-14). Hastaların klinik bulguları on beş günden az bir süre içinde kendini sınırlar ve püstüler döküntüler deskuamasyon ile düzelir. Genellikle iç organlar tutulmamasına rağmen sekonder infeksiyonlar sonucunda \%5 civarında mortalite bildirilmiştir (14).

\section{Histopatoloji}

Histopatolojik incelemelerde intraepidermal ve/ veya subkorneal spongiyoform püstüller saptanır. Papiller dermiste ödem, vaskülit, perivasküler eozinofil infiltrasyonu ve fokal keratinosit nekrozu gözlenen diğer bulgulardır $(4,9,15,16)$. Immünfloresan çalışmalar genellikle nonspesifiktir (16).

\section{Tanı}

AGEP tanısı hastanın öyküsü ve klinik bulgulara göre konulur, histopatolojik bulgular ancak tanıyı desteklemeye yardımcı olur. Aynı zamanda tanıda kullanılmak üzere çok uluslu farmako-epidemiyolojik vaka-kontrol çalışma grubu olan EuroSCAR tarafından oluşturulan AGEP tanı doğrulama skorlamasından da yararlanılabilir $(14,19,20)$. AGEP tanısı için 8 ile 12 arasında alınan bir puan kesin tanı koydurucu olarak belirtilmiştir (Tablo 1). Patogenezde tip IV aşırı duyarlılık reaksiyonunun rol aldığı bilindiğinden, hastalığın ortaya çıkmasına neden olduğu düşünülen ilacın standart topikal preparatlarıly veya sistemik formundan uygun sekilde hazırlanan topikal formu ile yama testi yapılabilir. Wolkestein ve arkadaşları (13), Watsky (17) ve Beylot ve arkadaşları (18) AGEP vakalarının yaklaşık olarak \%50'sinde yama testi ile pozitif sonuç elde etmişlerdir. Pozitif reaksiyonlarda klinik ve histolojik olarak benzer püstüler lezyonlar görülür. Literatürde diltiazem hidroklorür ile ilişkili bildirilen AGEP olgusunda yama testi yapılan alanın dışında da klinik olarak benzer püstüler lezyonların yayıldığı bildirilmiştir (16). Ülkemizden Özmen ve arkadaşlarının (21) yaptıkları çalışmada 6, 9, 11 ve 16 yaşındaki olgularda; sulbaktam-ampisilin, klindamisin, amikasin ve sefiksim kullanımı sonrası gelişen AGEP olguları bildirilmiş olup, bir olguda ampisilin ile yama testi pozitifliği göstermişlerdir. Yine antibiyotik dışı diğer ajanlarla tetiklenen AGEP olgularında da yama testi pozitifliği bildirilmiştir. Literatürde Poliak ve arkadaşları (22) tarafından radyokontrast madde kullanımı ile tetiklenen ve yama testi ile duyarlıı̆ı gösterilen bir pediatrik olgu bildirilmiştir. 


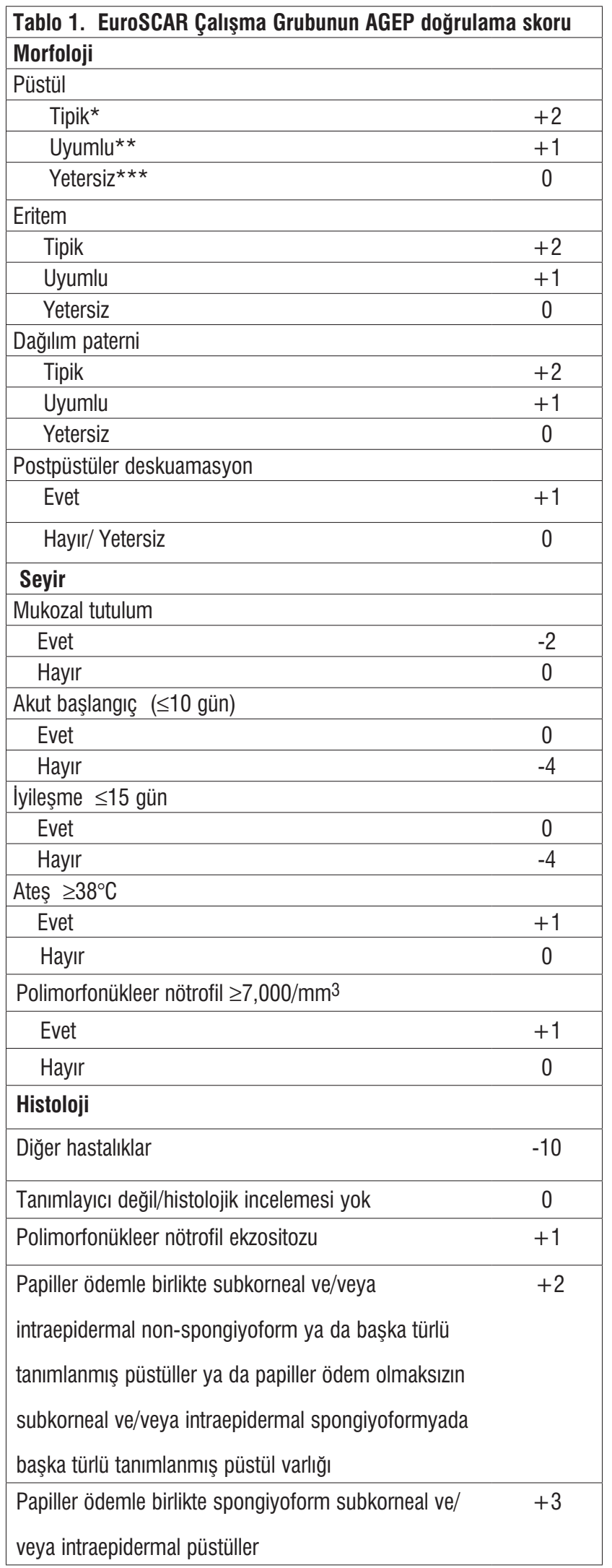

\section{Ayırıcı Tanı}

AGEP'in ayırıcı tanısında akla gelmesi gereken ilk hastalık püstüler psöriasistir. Klinik olarak psöriasis ve AGEP'teki püstüller ayırt edilemez. Histopatolojik olarak her iki hastalıkta da intraepidermal subkorneal püstüller gözlenir. Farklı olarak AGEP'de gösterilen eosinofil, nekrotik keratinosit, intersitisyal-dermal perivasküler infiltrat varlığı ve tortiyoze/dilate damar yokluğu püstüler psöriasiste bulunmamaktadır. Ayrıca püstüler psoriasiste farklı olarak dermiste papillomatozis ve akantoz vardır $(5,15,22$ 26). Klinik olarak da AGEP, akut başlangıç göstermesi, öncesinde ilaç kullanımı olması ve püstüllerin ortalama 9 gün içinde kaybolması ile püstüler psöriasisten ayrılır (15). Non-foliküler püstülozis ile karakterize olan AGEP, foliküler püstüllerin gözlendiği (bakteriyel folikülit, fronkül, akne benzeri erüpsiyonlar, püstüler kontak dermatit, dermatofit enfeksiyonları, primer vesiküler ve sekonder püstülasyon gösteren viral ekzantem, impetigo, Sweet sendromu ve stafilokokal haşlanmış deri sendromu) hastalıklardan kolaylıkla ayrılabilir $(25,26)$. Ayırıcı tanıda düşünülmesi gereken diğer iki hastalık da Sneddon-Wilkinson hastalığı (subkorneal püstülozis) ve subkorneal IgA dermatozudur. Bu hastalıklar subakut gelişen büyük püstüller olması ile AGEP'ten ayrılırlar (26). AGEP ve benzer hastalıkların ayırımı için EuroSCAR tarafından morfolojik özelliklere dayanılarak oluşturulan tanı doğrulama skorlamasıda kullanılabilir $(5,11,20,25,26)$.

\section{Tedavi}

Hastalığın özgül bir tedavisi yoktur ve tedavi genellikle semptomlara yönelik olarak yapılmaktadır. Hastaların çoğunda altta yatan nedenin ortadan kaldırılmasıyla ile birlikte spontan düzelme gözlenir. Genellikle lezyonun yaygınlığına ve hastanın genel durumuna göre sistemik antihistaminikler, topikal nemlendiriciler ve kortikosteroidli losyonlar tedavide yeterlidir (10,11,16-21).

Nadir olduğunu bildiğimiz bu kutanöz reaksiyonun pediatri pratiğinde sık kullandığımız ilaçlara bağlı olarak da ortaya çıkması nedeniyle, çocukluk döneminde görülen püstüler döküntülerin etiyolojisinde enfeksiyonlar kadar ilaç reaksiyonlarının da düşünülmesi gerektiği vurgulanmak istenmiştir.

\section{Kaynaklar}

1. Beylot C, Bioulac P, Doutre MS. Acute generalized exanthematic pustuloses (four cases). Ann Dermatol Venereol 1980;107:3748.

2. Chaabane A, Aouam K, Gassab L, Njim L, Boughattas NA. Acute generalized exanthematous pustulosis (AGEP) induced by cefotaxime. Fundam Clin Pharmacol 2010;24:429-32.

3. Freedberg IM, Eisen AZ, Wolff K, et al. Fitzpatrick's Dermatology in General Medicine 6th ed. New York: McGraw-Hill 2003:625-7. 
4. Roujeau JC, Bioulac-Sage P, Bourseau C, Guillaume JC, Bernard P, Lok C, et al. Acute generalized exanthematous pustulosis. Arch Dermatol 1991;127:1333-8.

5. Belhadjali H, Mandhouj S, Moussa A, Njim L, Amri M, Zakhama $A$, et al. Mercury-induced acute generalized exanthematous pustulosis misdiagnosed as a drugrelated case. Contact Dermatitis 2008;59:52-4.

6. Trevisi P, Patrizi A, Neri I, Farina P. Toxic pustuloderma associated with azithromycin. Clin Exp Dermatol 1994;19:280-81.

7. Davidovici BB, Naveh HP, Cagnano E, Halevy S; RegiSCAR Study Group. Acute generalized exanthematous pustulosis (AGEP) following intake of furosemide. Harefuah 2006;145:477-9.

8. Feio $A B$, Apetato M, Costa MM, Sá J, Alcantâra J. Acute generalized exanthematous pustulosis due to Coxsackie B4 virus. Acta Med Port 1997;10:487-91.

9. Manzano S, Guggisberg D, Hammann C, Laubscher B. Acute generalized exanthematous pustulosis: first case associated with a Chlamydia pneumoniae infection. Arch Pediatr 2006; 13:1230.

10. Klein N, Hartmann M, Helmbold P, Enk A. Acute generalized exanthematous pustulosis associated with recurrent urinary tract infections. Hautarzt 2009;60:226.

11. Momin SB, Del Rosso JQ, Michaels B, Mobini N. Acute generalized exanthematous pustulosis: an enigmatic druginduced reaction. Cutis 2009;83:291.

12. Samel AD, Dellavalle RP, Mockenhaupt M, et al. Drug eruptions. www.uptodate.com. Accessed 02.01.2013.

13. Wolkenstein P, Chosidow O, Fléchet ML, Robbiola 0, Paul M, Dumé $\mathrm{L}$, et al. Patch testing in severe cutaneous adverse drug reactions, including Stevens-Johnson syndrome and toxic epidermal necrolysis. Contact Dermatitis 1996;35:234-6.

14. Halevy S, Kardaun SH, Davidovici B, Wechsler J; EuroSCAR and RegiSCAR study group. EuroSCAR and RegiSCAR study group. The spectrum of histopathological features in acute generalized exanthematous püstülosis a study of 102 cases. Br J Dermatol 2010;163:1245-52.

15. Kardaun SH, Kuiper H, Fidler V, Jonkman MF. The histopathological spectrum of acute generalized exanthematous pustulosis (AGEP) and its differentiation from generalized pustular psoriasis. J Cutan Pathol 2010;37:1220-9.
16. Vicente-Calleja JM, Aguirre A, Landa N, Crespo V, GonzálezPérez R, Díaz-Pérez JL. Acute generalized exanthematous pustulosis due to diltiazem: confirmation by patch testing. Br. J. Dermatol 1997;137:837-9.

17. Watsky K.L. Acute generalized exanthematous pustulosis induced by metronidazole: the role of patch testing. Arch. Dermatol 1999;135:93-4.

18. Beylot C, Doutre MS, Beylot-Barry M. Acute generalized exanthematous pustulosis. Semin. Cutan. Med. Surg 1996;15:244-9.

19. Sidoroff A, Halevy S, Bavinck JN, Vaillant L, Roujeau JC. Acute generalized exanthematous pustulosis (AGEP)- a clinical reaction pattern. J Cutan Pathol 2001;28:113-9.

20. Sidoroff A, Dunant A, Viboud C, Halevy S, Bavinck JN, Naldi $L$, et al. Risk factors for acute generalized exanthematous pustulosis (AGEP) results of a multinational case-control study (EuroSCAR). Br J Dermatol 2007;157:989-96.

21. Ozmen S, Misirlioglu ED, Gurkan A, Arda N, Bostanci I. Is acute generalized exanthematous pustulosis an uncommon condition in childhood? Allergy 2010;65:1490-2.

22. Poliak N, Elias M, Cianferoni A, Treat J. Acute generalized exanthematous pustulosis: the first pediatric case caused by a contrast agent. Ann Allergy Asthma Immunol 2010;105:242-3.

23. Belda Junior W, Ferolla AC. Acute generalized exanthematous pustulosis (AGEP). Case report. Rev Inst Med Trop Sao Paulo 2005; 47:171-76.

24. Kaya A, Yıldız S, Balkan II, Eyvazov H, Bavunoglu I, Mert A. Acute generalized exanthematous pustulosis after ceftriaxone use resembling sepsis. J Infect Chemother 2012;18:112-4.

25. Cohen AD, Cagnano E, Halevy S. Acute generalized exanthematous pustulosis mimicking toxic epidermal necrolysis. Int J Dermatol 2001;40:458-61.

26. Fernando SL. Acute generalised exanthematous pustulosis. Australasian Journal of Dermatology 2012;53:87-92. 